
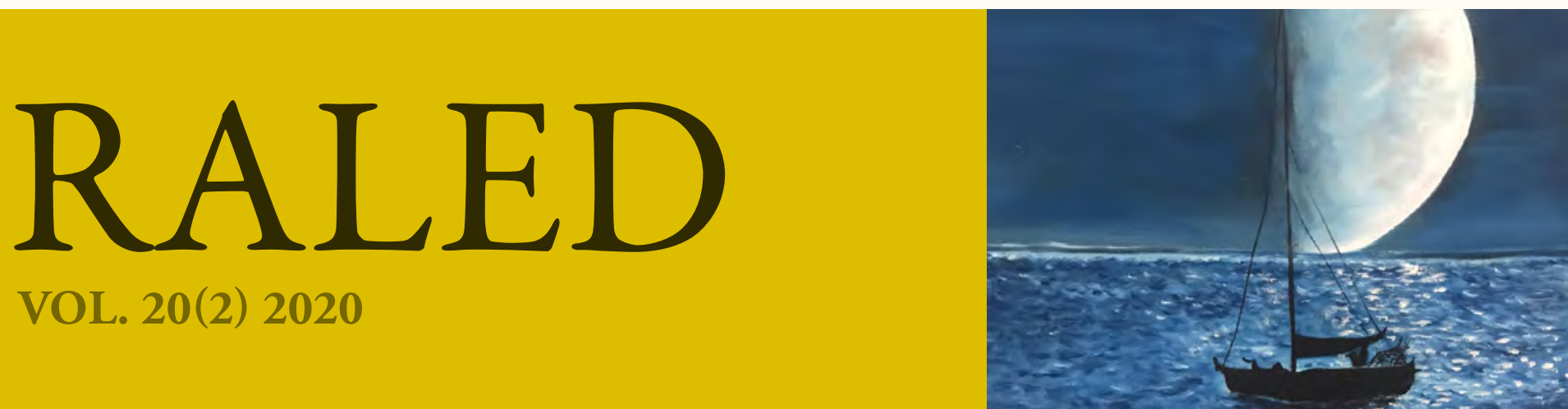

\title{
Pesquisas em Análise de Discurso Crítica produzidas no Brasil de 2008 a 2017
}

Critical Discourse Analysis research produced in Brazil from 2008 to 2017

\section{MARIA APARECIDA RESENDE OTTONI}

Universidade Federal de Uberlândia (UFU) Brasil

\section{IZABEL MAGALHÃES}

Universidade de Brasília (UnB)

Universidade Federal de Goiás (UFG)

Brasil

Recebido: 5 de agosto de 2020 | Aceito: 8 de outubro de 2020

DOI: 10.35956/v.20.n2.2020.p.112-132 


\section{RESUMO}

Este artigo é parte de uma pesquisa maior e nele apresentamos os resultados da análise de 36 teses e dissertaçôes, produzidas com base na Análise de Discurso Crítica (ADC), e defendidas de 2008 a 2017, em instituiçóes de ensino superior de quatro regióes brasileiras. Esses resultados permitiram-nos identificar lacunas nesses estudos, suas contribuiçóes teórico-metodológicas e o delineamento do estado da arte nesse campo. Além disso, possibilitaram-nos apresentar alguns aspectos a serem incluídos na agenda de pesquisa em ADC e podem jogar luz ao desenho de novas investigaçóes nesse campo no Brasil.

PALAVRAS CHAVE: Análise de Discurso Crítica. Pesquisas. Brasil. Estado da arte.

\section{ABSTRACT}

This article is part of a larger research and we present the results of the analysis of 36 theses and dissertations based on Critical Discourse Analysis (CDA), and defended from 2008 to 2017, in higher education institutions in four Brazilian regions. These results allowed us to identify gaps in these studies, their theoretical and methodological contributions and the outline of the state of the art in this field. In addition, they enabled us to present some aspects to be included in the CDA research agenda and may shed light on the design of new investigations in this field in Brazil.

KEYWORDS: Critical Discourse Analysis. Research. Brazil. State of the art.

\section{RESUMEN}

Este artículo es parte de una investigación más amplia y presenta los resultados del análisis de 36 tesis y disertaciones, producidas con base en el Análisis Crítico del Discurso (ACD), y defendidas entre 2008 y 2017, en instituciones de enseñanza superior de cuatro regiones brasileñas. Los resultados nos dieron la posibilidad de identificar las lagunas de estos estudios, sus contribuciones teóricas y metodológicas y el esbozo del estado del arte en este campo. Además, nos permitieron presentar algunos aspectos que se incluirán en la agenda de investigación del ACD y que pueden arrojar luz sobre el diseńo de nuevas investigaciones en este campo en Brasil.

PALABRAS ClAVE: Análisis Critico del Discurso. Investigaciones. Brasil. Estado del arte. 


\section{Introduçáo}

A perspectiva de estudos críticos da linguagem foi introduzida no Brasil por Izabel Magalhães, em um artigo publicado na revista D.E.L.T.A. (PUC/SP) em 1986: "Por uma abordagem crítica e explanatória do discurso". Magalhães foi aluna de Fairclough, na Universidade de Lancaster, Reino Unido, nas décadas de 1970 e 1980, e, nessa instituição e depois no Brasil, teve a oportunidade de acompanhar o desenvolvimento da vasta obra de Fairclough, iniciada com a publicaçáo de um artigo no periódico internacional Journal of Pragmatics (1985). Nessa época, os estudos da linguagem no Brasil eram dominados pelo paradigma estruturalista e gerativista, de forma que Magalhães encontrou resistência na Universidade de Brasília para criar uma linha de estudos nessa instituição voltada para a Análise de Discurso Crítica (ADC), tendo ministrado a primeira disciplina, no Programa de Pós-Graduação em Linguística (PPGL) em 1986.

No entanto, não se pode deixar de mencionar que já havia nessa época, na Universidade Estadual de Campinas (Unicamp), uma linha consolidada de estudos do discurso de orientação francesa. Gradualmente, outras instituiçóes desenvolveram seus projetos institucionais de estudos críticos do discurso, destacando-se a influência de Carmen Rosa Caldas-Coulthard (1997), na Universidade Federal de Santa Catarina (UFSC).

Desde a introdução da ADC no Brasil, inúmeros trabalhos foram produzidos por pesquisadores de diferentes instituiçóes de ensino superior, com base nessa perspectiva teórico-metodológica. E, neste artigo, apresentamos resultados parciais de um estudo desenvolvido de agosto de 2017 a julho de 2018, durante o estágio de pós-doutoramento realizado sob a supervisão da Profa. Dra. Izabel Magalhães, no Programa de Pós-Graduação em Linguística da Universidade de Brasília. O objetivo geral deste estudo é mapear as pesquisas desenvolvidas no Brasil, por pesquisadores brasileiros, de 2008 a 2017, com base no aporte da ADC, tomando como corpus de análise artigos publicados em periódicos da área, Qualis B2 a A1, dissertaçóes e teses de programas de pós-graduação acadêmicos e trabalhos finais defendidos no Programa de Pós-Graduação Mestrado Profissional em Letras (Profletras).

Neste recorte, focalizamos a análise de dissertaçóes e de teses defendidas em 6 (seis) programas de pós-graduação acadêmicos de quatro instituiçóes de ensino superior, de quatro regióes brasileiras. Nós partimos das seguintes questóes de pesquisa: a) Quais são os temas em foco nessas produçôes?; b) Quais são os objetos de estudo e análise tomados?; c) Qual a abordagem de ADC adotada?; d) Quais são as teorias postas a dialogar com a ADC - abordagem considerada transdisciplinar?; e) Quais são as categorias de análise selecionadas?; f) Quais são os principais pressupostos metodológicos adotados e instrumentos de geração e coleta de dados usados?; g) Quais são as principais contribuiçôes dessas pesquisas?; h) Quais são as lacunas apontadas nesses trabalhos?; i) Quais aspectos podem ser incluídos em uma agenda de pesquisa em ADC?

Considerando os objetivos e questóes expostos, a pesquisa proposta pode ser denominada como "estado da arte" ou "estado do conhecimento", conforme Ferreira (2002) e Rossetto et al. (2013). Para Ferreira (2002: 258), "Nos últimos quinze anos, no Brasil e em outros países, tem se produzido um conjunto significativo de pesquisas conhecidas pela denominação 'estado da arte". Tais pesquisas "permitem sistematizar um determinado campo do conhecimento, mapear e reconhecer as produçóes, identificando temáticas e abordagens dominantes e emergentes, bem como lacunas e campos inexplorados abertos à pesquisa, num recorte temporal definido" (Rossetto et al. 2013: 1). 
Em relação à $\mathrm{ADC}$, algumas pesquisas do tipo "estado da arte" já foram feitas, como a de Pedrosa e Cruz (2012), a de Magalhães (2007) e a de Camargo (2014). Todas essas investigaçóes trouxeram uma contribuição de suma relevância para a área do conhecimento e, especialmente, para os pesquisadores que trabalham com ADC, mas nenhuma teve o escopo do nosso trabalho e, dado o crescimento de interessados nessa perspectiva teórico-metodológica e a diversidade de abordagens em $\mathrm{ADC}$, há ainda a necessidade de investimento em pesquisas que revelem o que se tem feito no Brasil, com base na $\mathrm{ADC}$, que identifiquem as potencialidades e lacunas desses estudos e que reflitam sobre possíveis novos caminhos da ADC no Brasil. Nesse sentido, nosso estudo procura preencher essa lacuna.

\section{O percurso metodológico}

Para um primeiro levantamento, fizemos uma pesquisa pelo Google, partindo dos seguintes termos de busca: Análise de Discurso Crítica; Análise Crítica do Discurso; ADC; ACD; Critical Discourse Analysis; CDA, que identificou produçóes de diversos tipos. Logo após, fizemos uma busca no catálogo de teses e dissertações da CAPES (http://catalogodeteses.capes.gov.br/catalogo-teses/\#!/), usando os mesmos termos, e uma pesquisa nos programas da área de Linguística e Literatura para identificarmos quais docentes trabalham com a ADC. Os resultados revelaram dissertaçóes e teses desenvolvidas com base em ADC em mais de 20 (vinte) instituiçóes de ensino superior (IES). Dada a necessidade de delimitação, analisamos quais IES contavam com maior número de docentes vinculados a programas de pós-graduação acadêmicos e que trabalham com ADC, o que resultou em duas: a UFPE e a UnB. Contudo, consideramos que, para melhor representar a produção no Brasil, seria relevante incluir mais IES e tentar contemplar as cinco regiôes do país. Assim, analisamos quais outras IES, das regiôes norte, sudeste e sul contavam com maior número de professores com o perfil determinado. Essa análise evidenciou a UFMG, na região Sudeste e a UFSC, no Sul. Na regiâo norte, não encontramos representatividade relativa ao foco do estudo. Dessa forma, foram selecionadas quatro IES: a UFMG; a UFPE; a UFSC; e a UnB.

Após isso, passamos à investigação das teses e dissertaçóes defendidas de 2008 a 2017 nos programas da área dessas IES. Para isso, acessamos o repositório da biblioteca digital de cada IES. Nela, incluímos o nome do/a orientador/a, conforme levantamento inicial, e, considerando o recorte temporal, fizemos uma primeira análise dos trabalhos resultantes da pesquisa de modo a identificar se tomavam a ADC como base teórico-metodológica. Para essa identificação, observamos se havia menção à abordagem no título, no resumo e no sumário, inicialmente. Em seguida, fizemos uma busca no texto a partir dos termos já mencionados. Além disso, acessamos novamente o catálogo de teses e dissertaçóes da CAPES, no qual realizamos também as buscas pelo nome do/a orientador/a e pelos mesmos termos. Outrossim, acessamos o currículo lattes dos/as pesquisadores/as e investigamos, na parte referente às orientaçóes concluídas, se não havíamos deixado de incluir alguma pesquisa no levantamento. Durante todo esse processo, elaboramos um quadro no qual registramos o nome da IES, do Programa, a área de concentração e linha de pesquisa, o nome do/a docente, a classificação do trabalho - tese ou dissertaçáo -, o título e o/a autor/a do trabalho. Dada a sua dimensão, não foi possível incluí-lo neste artigo. No quadro 1, representamos o resultado numérico dessas buscas: 
Dissertaçôes e teses defendidas de 2008 a 2017 em programas da área de Linguística e Literatura nas quatro IES selecionadas.

\begin{tabular}{lcccc} 
& UFMG & UFPE & UFSC & UNB \\
DISSERTAÇOEES & 08 & 10 & 15 & 59 \\
\hline TESES & 07 & 14 & 07 & 49 \\
\hline TOTAL & 15 & 24 & 22 & 108 \\
\hline TOTAL GERAL & \multicolumn{5}{c}{164} \\
\hline
\end{tabular}

Tendo em vista essa quantidade de trabalhos representada no quadro 2, foi necessário fazermos um novo recorte. Para isso, estabelecemos um critério, segundo o qual foram incluídos somente os trabalhos dos/as pesquisadores/as que já tinham pelo menos uma orientação de tese, construída com base em aportes da ADC, concluída dentro do período de 2008 a 2017. Chegamos, assim, a 130 (cento e trinta) teses e dissertaçóes. Entretanto, consideramos que tal número ainda era elevado e que não seria possível dar conta da análise, em conformidade com os objetivos da pesquisa, no prazo de que dispúnhamos. Para uma nova delimitação, estabelecemos como critério selecionar pelo menos um trabalho de cada pesquisador e um trabalho de cada ano que compóe o período de 2008 a 2017, de modo que, em relação a cada IES, tivéssemos a representação da produçáo de diferentes docentes e de diferentes anos. A seleçâo deu-se da seguinte forma, a partir do quadro geral com os 130 (cento e trinta) trabalhos já encontrados:

a) nos casos em que, em relação a alguns anos, havia apenas um trabalho em cada IES, a inclusão foi feita automaticamente para procurar garantir a representação da produção em todos os anos do período;

b) nos casos em que havia mais de um trabalho do mesmo ano, levamos em conta a necessidade de contemplar diferentes orientadores, o equilíbrio entre o número de dissertaçóes e de teses do programa e a diversidade temática.

O total resultante dessa seleção é 36 trabalhos, sendo 17 dissertações e 19 teses, o que representamos no quadro 2 a seguir:

\section{QUADRO 2}

Resultado da seleção final das teses e dissertações a serem analisadas.

\begin{tabular}{lcccc} 
& UFMG & UFPE & UFSC & UNB \\
DISSERTAÇÓES & 04 & 03 & 04 & 06 \\
\hline TESES & 05 & 06 & 04 & 04 \\
\hline TOTAL & 09 & 09 & 08 & 10 \\
\hline TOTAL GERAL & \multicolumn{5}{c}{36} \\
\hline
\end{tabular}


Após a definição dos trabalhos que comporiam o corpus, etiquetamos cada um, com a inclusão da referência à natureza do trabalho: $\mathrm{D}$ para dissertação e $\mathrm{T}$ para tese; ao número de ordem do trabalho na listagem de cada IES: 1, 2, 3...; à/s inicial/is do nome do/a orientador/a; ao ano de defesa; e à sigla da IES, como neste exemplo: (D2J2009UFMG). Em seguida, organizamos essas pesquisas em pastas por IES, no computador. Na sequência, fizemos várias leituras de cada uma e a análise, tendo em vista as questóes de pesquisa e os objetivos propostos. Na seção seguinte, expomos e discutimos os resultados da análise, os quais foram organizados a partir dessas questóes.

\section{Análise dos dados e discussáo dos resultados}

Para respondermos à primeira questão de pesquisa "Quais são os temas em foco nessas produçóes em ADC no Brasil?", relemos o resumo e a introdução de cada uma. Identificamos uma diversidade de temas que têm sido contemplados nos trabalhos construídos com base em pressupostos da ADC como: práticas de leitura e de escrita da população em situação de rua e de vulnerabilidade social, representaçóes discursivas do Movimento Nacional da População de Rua, aborto, açóes afirmativas, racismo, desigualdade racial, consumo, violência doméstica, letramentos, meio ambiente, saúde, escândalos políticos, autoimagem corporal de mulheres, interação entre fonoaudiólogo/a e mães de crianças pacientes, multimodalidade em livros didáticos, identidade social da mulher na mídia, de políticos envolvidos em esquemas de corrupção em instituiçóes públicas e de homossexuais, publicidade bancária, obesidade e saúde, discurso jornalístico e midiático.

Pardo (2010) destaca, sobre os temas em foco nas pesquisas latino-americanas, que

Latin American researchers, nevertheless, take their subject-matter often unreflectingly from European studies, leaving out a wide range of vital local issues. Among them we could mention: the discourse of the poor; the discourse of outpatient treatment of psychiatric cases; media discourse on illegal drugs, human trafficking and media discrimination; the discourse about military dictatorship, the Mothers and Grandmothers of the Plaza de Mayo, human rights, the Malvinas/Falklands war, the Colombian civil war and other armed conflicts; and the discursive treatment of corruption, lack of access to education, domestic violence, teenage pregnancy, alcoholism and drug addiction. (Pardo 2010: 187)

Acreditamos que o cenário vem sofrendo alguma modificação, pois os resultados da análise das dissertaçôes e teses mostram o enfoque em "questôes locais vitais" que, segundo Pardo (2010), têm sido deixadas de fora por pesquisadores latino-americanos, tais como: açóes afirmativas; movimentos sociais; população em situação de rua e de vulnerabilidade social; violência doméstica; corrupção.

Com relação aos dados analisados nos 36 estudos para a abordagem dos temas, ${ }^{1}$ o resultado revelou que em 21 foram analisados dados pré-existentes ao desenvolvimento da pesquisa, como

1 Para a identificação dos dados analisados, relemos o resumo, a introdução e a metodologia de cada estudo. 
exemplares de gêneros da esfera jornalística, da esfera publicitária, documentos diversos e textos de livros didáticos; em 8, os dados foram gerados na interação com os sujeitos participantes, em pesquisa de cunho etnográfico; e, em 7, a análise compreendeu os dois tipos de dados, conforme gráfico 1 a seguir:

\section{GRÁFICO 1}

Tipos de dados analisados.

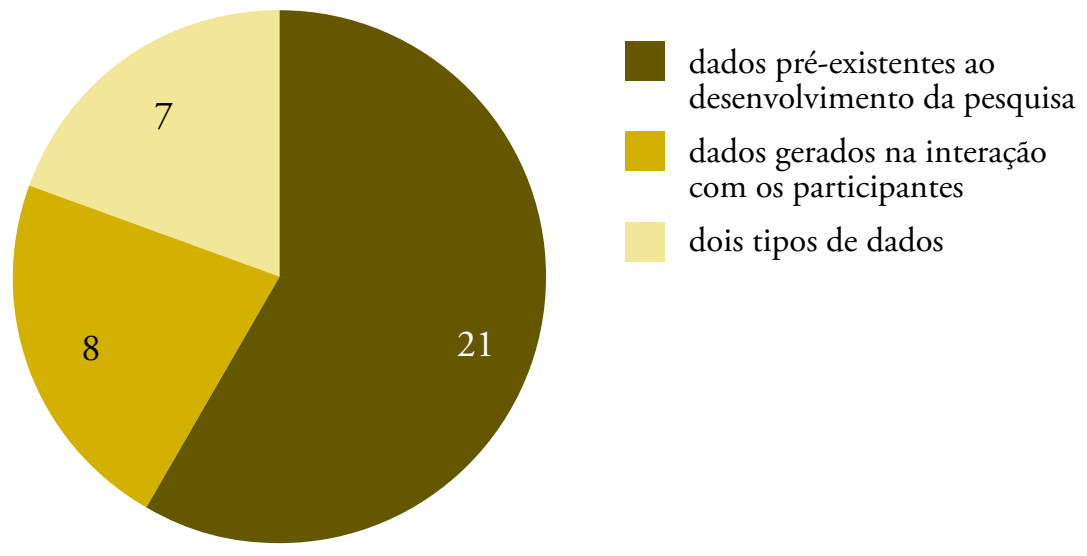

O gráfico 1 demonstra que ainda há uma tendência de pesquisa centrada em ADC que se volta só para a análise de dados pré-existentes ao desenvolvimento do estudo, o que tem sido criticado por vários/ as pesquisadores/as (Magalhães 2000, 2006; Resende 2010; Magalhães, Martins e Resende 2017).

De acordo com Resende (2010), tendo em vista a abordagem dialético-relacional, especialmente,

CDA only in documentary data (and the majority of approaches is only documental, according to Meyer 2003) do not manage to realise epistemologically all the potential of the ontological perspective adopted by CDA, based upon a composed stratified social reality of networks of practices. There exists then incoherence between CDAs ontological perspective and its tradition of isolated documental analysis. (Resende 2010: 200)

Considerando o foco da ADC na análise das práticas sociais e de problemas sociais, em seus aspectos semióticos, cada vez mais tem sido incentivada e valorizada a articulação da ADC com a etnografia, pois ela

representa um avanço para a ADC, do mesmo modo como a etnografia também pode tirar vantagens de uma articulação com métodos para análise de textos e interaçôes desenvolvida por analistas de discurso [...] Não se trata, contudo, de simples combinaçáo de métodos. A relação a se estabelecer deve ultrapassar a relação interdisciplinar para se constituir como transdisciplinar, o que implica a operacionalização. Métodos para análise de texto e categorias da ADC podem ser compatibilizados com tradiçóes etnográficas, assim como estas podem ser recontextualizadas para servirem a pesquisas discursivas críticas. Trata-se, pois, de um diálogo profícuo, mas que exige reflexão e rompimento de fronteiras (Magalhães, Martins e Resende 2017: 158). 
Como esses/as pesquisadores/as, nós também acreditamos que essa articulação entre a ADC e a etnografia é necessária e importante para os estudos que não intentam investigar apenas a representação discursiva de uma determinada prática social, mas, sim, a própria prática, o que implica na análise da conjuntura, das relaçôes dialéticas entre o momento semiótico e os outros momentos da prática social, entre textos e outros elementos dos eventos sociais e na seleção de um tópico de pesquisa que se relaciona com o problema social em foco ou aponta para ele e que pode ser produtivamente abordado de um modo transdisciplinar (Fairclough 2009).

No tocante aos dados pré-existentes ao desenvolvimento da pesquisa, foram analisados: a) gêneros das esferas jornalística, publicitária e propagandística, como editoriais e artigos de opinião, reportagens, capas de revistas, escaladas de telejornal, notícias entrevistas publicadas em site de jornal, anúncios televisivos brasileiros e ingleses; propagandas, campanha de conscientização ambiental; b) documentos: discursos de políticos disponíveis no site da secretaria de imprensa da presidência da república e no site da Folha de S. Paulo; pronunciamentos políticos; projetos educacionais de caráter extensionista, projeto pedagógico de uma escola, de faculdades particulares; o Currículo da Educação Básica do Distrito Federal; Editais de Chamada Pública do FNDE para livros didáticos; leis; resoluçóes; decretos; Diretrizes Curriculares da Educação Nacional; Declaração Mundial sobre Educação para Todos; Declaração Universal dos Direitos Humanos; discursos de todos os participantes com direito de fala nas três primeiras audiências públicas interativas do Senado Federal referentes à sugestáo no 15 , de 2014 ; documentos sobre a trajetória da sugestáo coletados no site do Senado Federal; a carta de princípios do Movimento Nacional da População em Situação de Rua (MNPR) e o plano de ação desse movimento; c) livros didáticos.

Assim, no tocante à pesquisa que toma dados pré-existentes ao seu desenvolvimento, predomina a análise de textos, associados à prática social jornalística, de diferentes gêneros do discurso publicados em sites, em jornais, revistas e telejornais, como representado no gráfico 2 a seguir:

\section{GRÁFICO 2}

Práticas sociais das quais os textos analisados são parte.

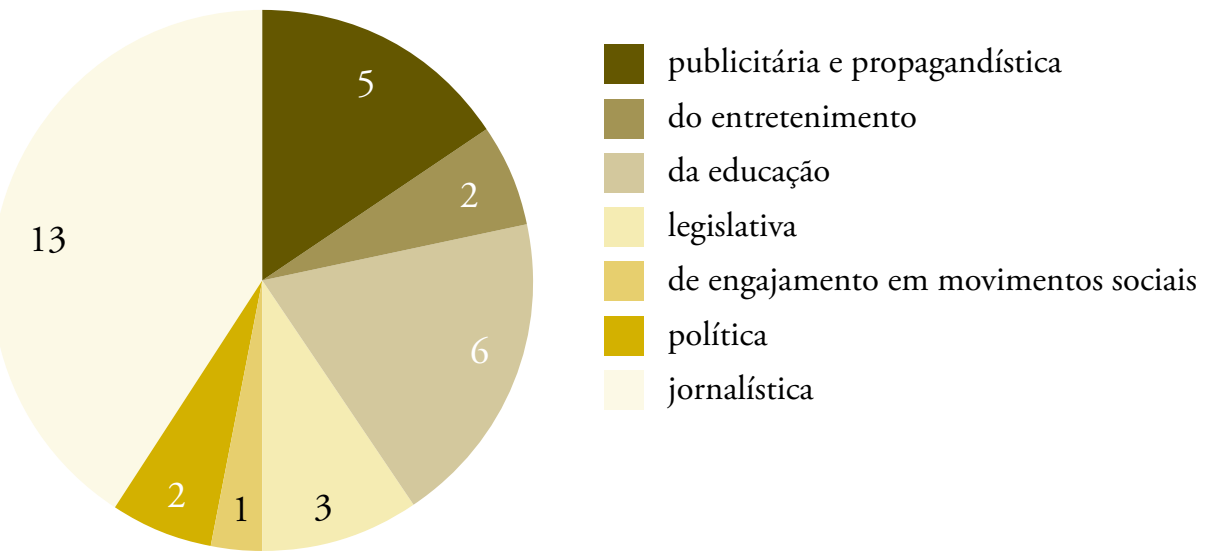

No que diz respeito aos dados gerados na interação com os sujeitos participantes em uma pesquisa de cunho etnográfico, tal geração se deu por meio de: observação participante, diário de campo, questionários, entrevistas, um teste sobre satisfação corporal e um denominado Escala de Silhuetas, gravaçôes em vídeos da interpretação simultânea de um texto narrado oralmente em Língua 
Portuguesa e interpretado para a Língua de Sinais Brasileira; textos escritos por alunos, em suas várias versóes, narrativas de vida escrita por estudantes; relatos orais. No gráfico 3, representamos a utilização de cada um desses instrumentos de geração de dados:

\section{GRÁFICO 3}

Instrumentos de geração de dados utilizados nas teses e dissertações.

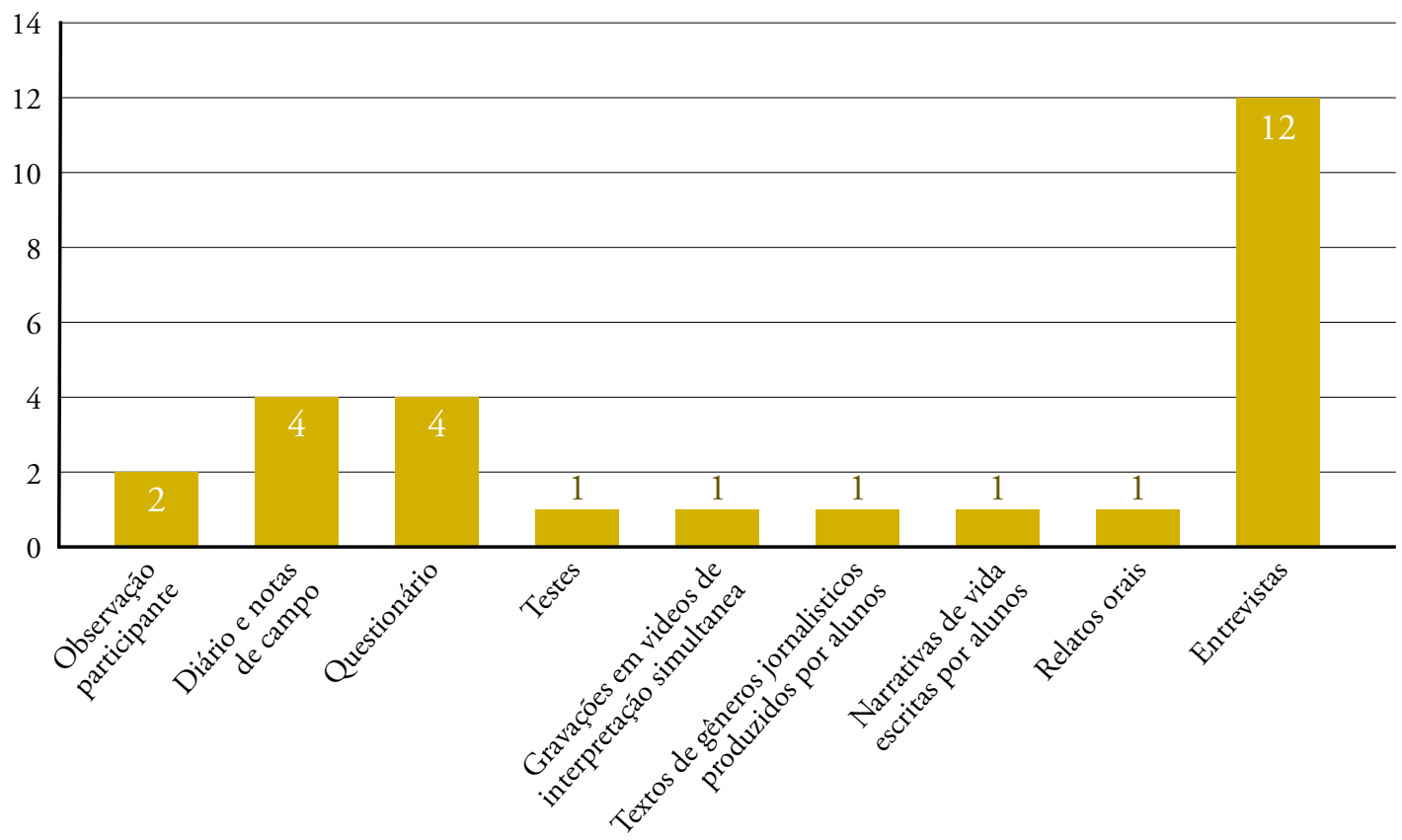

O gráfico 3 revela que dos 15 estudos nos quais são analisados dados oriundos da interação com os sujeitos participantes, em uma pesquisa de cunho etnográfico, em 12 a entrevista foi um instrumento utilizado. Foram realizadas entrevistas semiestruturadas, narrativas, individuais e grupais, o que aponta para a produtividade desse instrumento. Conforme McCracken (1988: 9), a entrevista é "um dos mais poderosos métodos qualitativos", e acreditamos que esse é um dos motivos pelos quais ela foi o instrumento mais utilizado.

Todas as teses e dissertaçóes adotaram a abordagem qualitativa de pesquisa e, em 10 trabalhos, recorreu-se também à abordagem quantitativa, sendo 04 da UFMG, 03 da UFPE, 1 da UFSC e 2 da UnB.

É relevante destacar que na maioria dos estudos há uma apresentação organizada, detalhada e justificada de todos os procedimentos metodológicos adotados, construindo, assim, um desenho claro da pesquisa, o que pode fornecer uma valiosa contribuição especialmente para os/as que estão iniciando em pesquisas embasadas na ADC.

Ainda no que concerne à metodologia, observamos que alguns/mas estudiosos/as recorreram à Linguística de Corpus, notadamente à ferramenta Word Smith Tools; ao método sincrônico-diacrônico de análise linguística de textos (MSDALT); e, para análise da imagem em movimento, a diferentes propostas, como o protocolo de análise de imagens em movimento de Rose (2007), à proposta de análise multimodal interacional desenvolvida principalmente por Norris $(2004,2011)$ e Jones e Norris (2005), ao arcabouço proposto por Painter e Martin (2011) e ao modelo multimodal de transcrição de filme proposto por Baldry e Thibault (2006). 
No tocante às abordagens de ADC adotadas, várias são elencadas por Wodak e Meyer (2009) e investigamos qual foi prevalente nas 36 teses e dissertaçóes analisadas. Identificamos que: a) a abordagem dialético-relacional é adotada em 27 trabalhos; a sociognitiva, em 2; a histórico-discursiva, em 01 ; e a dialético-relacional em conjunto com a sociocognitiva, em 06 , conforme gráfico 4 a seguir:

\section{GRÁFICO 4}

Abordagens de ADC utilizadas nas dissertaçóes e teses.

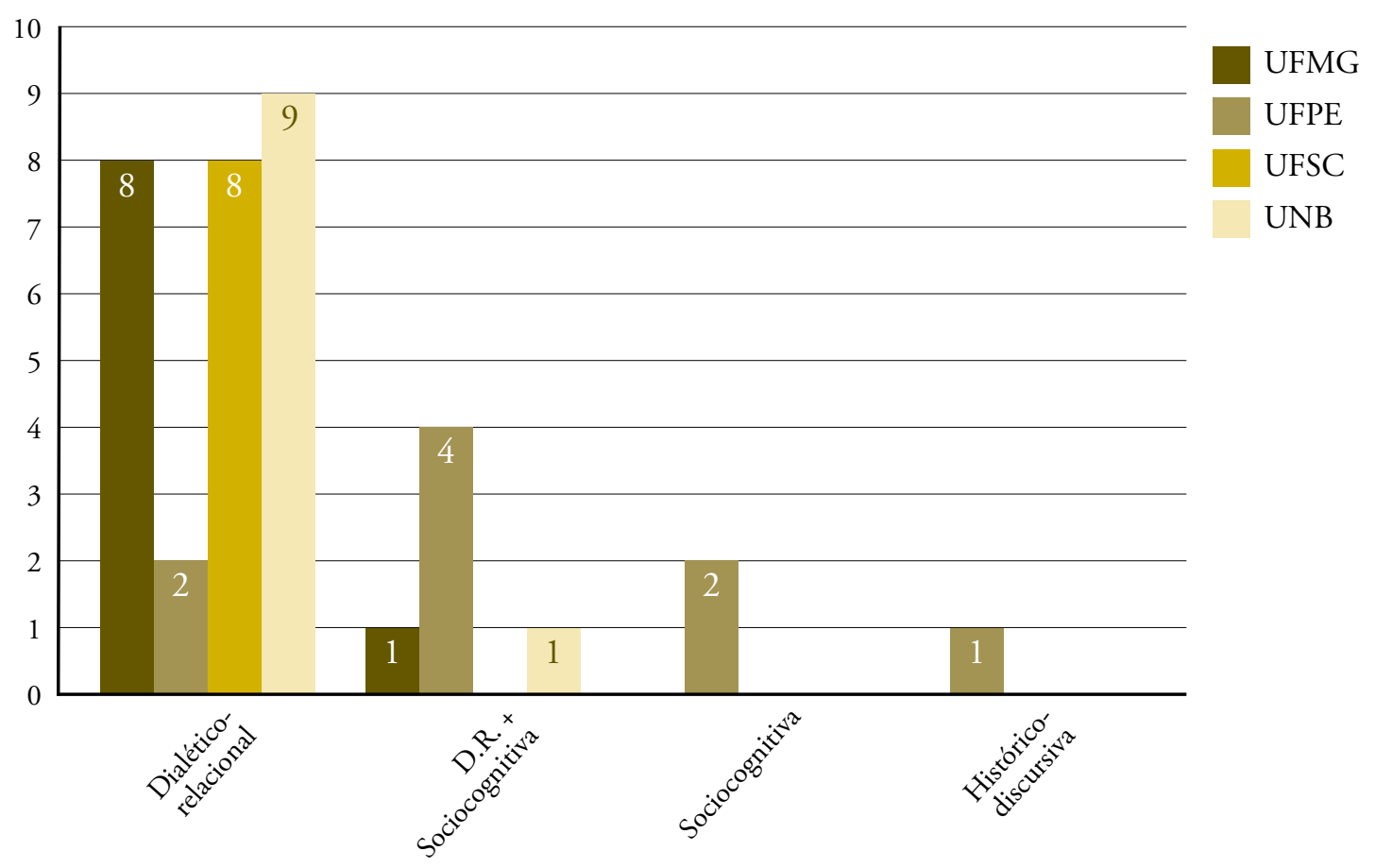

Esses dados explicitam a predominância da abordagem faircloughiana de ADC nos trabalhos e pouca utilização das outras abordagens, o que acreditamos ser representativo da produção em ADC no Brasil e merece reflexão. Tendo em vista o fato de que não há uma abordagem melhor que outra, é relevante investigar, futuramente, o que tem feito com que a maioria dos/as pesquisadores/as que trabalham com ADC tome como base a abordagem dialético-relacional. Chama a atenção a articulação da abordagem dialético-relacional e da sociocognitiva, em seis trabalhos, o que não tem sido comum no Brasil e joga luz à produtividade do diálogo entre as diferentes abordagens de ADC, o que pode contribuir para a ruptura de possíveis barreiras.

Outro aspecto investigado em nosso estudo é concernente ao diálogo da ADC com outras teorias e estudos. De acordo com Chouliaraki e Fairclough (1999: 2), a ADC é uma teoria e um método que estão em relação dialógica com outras teorias sociais e linguísticas e métodos, com os quais deve-se envolver de um modo 'transdisciplinar', e não simplesmente interdisciplinar. Nessa perspectiva, observamos que, tendo em vista o problema em foco em cada estudo e os objetivos, várias perspectivas teóricas e metodológicas e diferentes estudos foram acionados e colocados em diálogo com a ADC. Na figura 1 a seguir, procuramos representar essa diversidade: 


\section{FIGURA 1}

As perspectivas teórico-metodológicas e os estudos articulados à ADC nas dissertaçóes e teses.

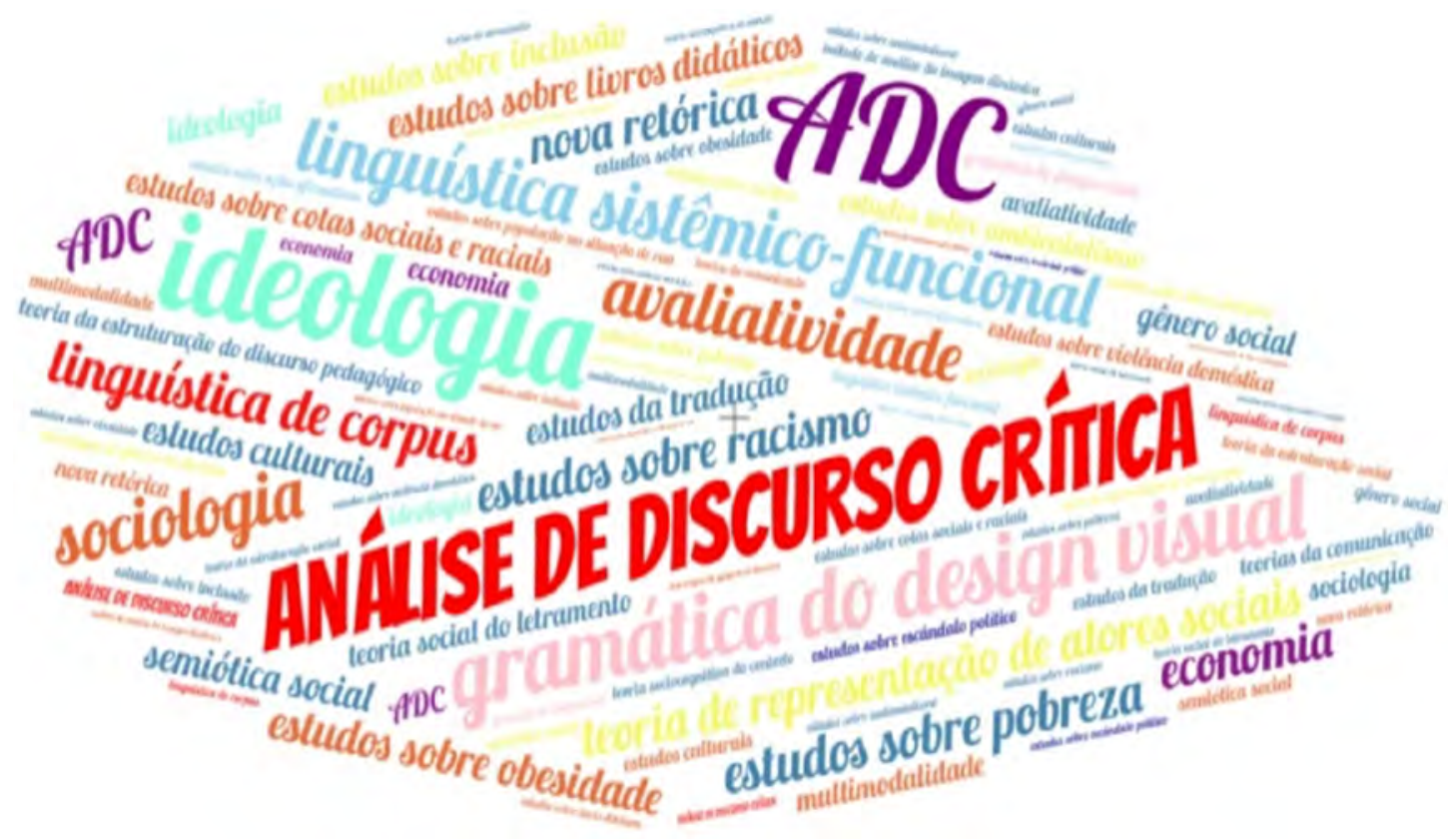

Conforme Ramalho e Resende (2011: 107), as "pesquisas em análise de discurso são empreendimentos complexos, que não se limitam à análise textual. Ao contrário, exigem numerosas leituras em Ciências Sociais, reflexóes sociais e/ ou trabalho de campo.”. A figura 1 ilustra essa complexidade e evidencia a necessidade de leituras não só em Ciências Sociais Aplicadas como também em Ciências Humanas, em Ciências da Saúde etc., a depender do problema a ser investigado.

A análise das 36 dissertaçóes e teses revelou a recorrência maior do diálogo da ADC com: a LSF; os Estudos Culturais; a Gramática do Design Visual (GDV); os estudos sobre gênero social; e a teoria de representaçáo de atores sociais. Revelou ainda que, das categorias de análise propostas nas diferentes abordagens de ADC, foram utilizadas em maior escala as seguintes, em ordem decrescente: a interdiscursividade; a transitividade; a intertextualidade; a representação de atores sociais; a modalidade; as escolhas lexicais/vocabulário; os modos de operação da ideologia; a coesão (referenciação, relaçóes semânticas) e a avaliação. Além dessas, várias outras categorias foram acionadas, incluindo as propostas por Kress e van Leeuwen (1996) na GDV para a análise dos significados representacional, interativo e composicional e algumas sociológicas, como: habitus, agente, contexto, regras e recurso.

\section{Contribuiçóes teóricas e metodológicas}

Cada trabalho analisado constitui uma contribuição para o entendimento do papel da linguagem nas práticas sociais e para a análise de diferentes problemas sociais, partindo de seu aspecto discursivo. Cada resposta dada às questóes propostas nas investigaçóes e cada resultado de análise evidenciam o valor das pesquisas em foco neste estudo. Contudo, não nos é possível 
enumerar todos neste artigo. Assim, elencamos algumas contribuições teóricas e metodológicas que consideramos mais salientes:

1. Utilização de instrumentos de geração e coleta de dados comuns a outras áreas do conhecimento em pesquisa da área da Linguística (Loiola 2014) e de ferramentas como Wmatrix; ${ }^{2}$

2. a utilização do ELAN (EUDICO - Linguistic Annotator), "projetado para a análise de línguas, mais especificamente para a língua de sinais e de gestos" (Nicoloso 2010: 128);

3. a proposição de novas categorias para análise do nível de satisfação da autoimagem corporal (Loiola 2014);

4. a abordagem da multimodalidade, por meio da articulação da ADC com diferentes perspectivas de análise da imagem em movimento e estática, como mencionamos quando tratamos da metodologia, além da articulação com a GDV mais comumente presente nas pesquisas em ADC no Brasil;

5. a aplicação do Método Sincrônico-Diacrônico de Análise Linguística de Textos (MSDALT), criado por Maria Laura Pardo em 2011 (Santos 2017), e sua articulação com a LSF, o que constitui uma novidade em se tratando de teses e dissertaçóes produzidas no Brasil e marca uma perspectiva decolonialista;

6. a articulação de mais de uma abordagem de ADC no desenvolvimento de um mesmo estudo, o que não tem sido comum no país, joga luz à produtividade do diálogo entre as diferentes abordagens de ADC e pode contribuir para a ruptura de possíveis barreiras.

Além dessas contribuiçóes enumeradas, a representação de uma nova escola voltada para as abordagens sobre discurso e pobreza em ADC na América Latina (Santos 2017) constitui uma contribuição teórica. ${ }^{3}$ Tendo-a em vista, podemos reconfigurar o quadro proposto por Wodak e Meyer (2009: 20), incluindo a abordagem latino-americana sobre discurso e pobreza e outras contribuiçóes latino-americanas, especialmente as geradas por mulheres (Resende 2019).

Outro aspecto que nos chamou a atenção é a materialização de uma crítica explanatória coerente com as escolhas teórico-metodológicas, destacada como um capítulo em uma tese (Santos 2017), ${ }^{4}$ o que nos pareceu inovador e muito relevante, pois dá relevo a essa açáo fundamental na pesquisa em ADC. Igualmente, merece destaque a preocupação de alguns/mas pesquisadores/as - 0

2 "Wmatrix is a software tool for corpus analysis and comparison. It provides a web interface to the English USAS and CLAWS corpus annotation tools, and standard corpus linguistic methodologies such as frequency lists and concordances. It also extends the keywords method to key grammatical categories and key semantic domains." http://ucrel.lancs.ac.uk/wmatrix/

3 Santos (2017: 51) entende "'escola' como um ponto temático central sobre o qual se produzem construtos do conhecimento - epistemológicos e metodológicos."

4 O autor náo numerou o capítulo como fez com os demais, mas o configurou como tal. 
que deveria ser comum a todos/as - com o diálogo com a comunidade participante e retorno a ela dos resultados obtidos (Acosta 2012; Santos 2017).

\section{Algumas lacunas}

A análise apontou alguns aspectos que merecem atençáo dos/as investigadores/as e que constituem, a nosso ver, lacunas em trabalhos pautados na ADC.

Observamos que em alguns estudos o/a autor/a destaca que a pesquisa traz contribuiçóes para, por exemplo, uma melhor compreensão de determinado problema social, para incentivar o planejamento e execução de projetos que minimizem tal problema, mas não há referência alguma ao retorno dos resultados do estudo aos/às participantes, aos órgãos ou autoridades diretamente envolvidos, e discussão com eles/as de estratégias de divulgação desses resultados fora do meio acadêmico. Igualmente, são elencadas algumas contribuições que pressupóem a leitura das pesquisas por um público amplo, o que não é a realidade do nosso país, onde, em geral, as dissertaçóes e teses são lidas especialmente por professores/as pesquisadores/as e por pós-graduandos/as, como exemplificam os três excertos a seguir:

(a) D2J2009UFMG - [...] cremos contribuir para uma melhor compreensão das articulaçôes discursivas e culturais dos moradores em situação de rua. Com isso, esperamos motivar e incentivar o planejamento e a execuçāo de projetos que valorizem essas práticas e ampliem as oportunidades de participação dessa população em eventos de letramento, a partir das experiências da própria comunidade. (Santos 2009: 161)

(b) D7S2010UFMG - acreditamos que a análise crítica e linguistica destes puderam fornecer indícios para a compreensão das especificidades da linguagem em uso na situação de interação no contexto clinico, bem como as expectativas, demandas e necessidades dos sujeitos participantes. Ressaltamos também que os resultados encontrados podem contribuir para que ofonoaudiólogo tenha um diálogo efetivo e sistemático com as mães, que possa implicar na construção de outro tipo de relação social, mais emancipatória e igualitária. (Rodrigues 2010: 135)

(c) T5S2014UFMG - Esta pesquisa também propiciou contribuiçóes empiricas a partir da melhor compreensão dos aspectos envolvidos com a autoimagem corporal da mulher brasileira, por meio do discurso. [...] Além disso, os resultados aqui obtidos permitirão às próprias mulheres tomarem consciência do que contribui positiva e negativamente para a construção de suas autoimagens corporais. (Loiola 2014: 150)

Ademais, alguns/mas procuram, nas consideraçóes finais, estabelecer uma relação da pesquisa com o ensino, o que é positivo, mas dado o fato de a pesquisa não ter sido desenvolvida com foco no ensino, de que a maioria dos professores da educação básica no Brasil não é leitor das dissertações e teses defendidas e dada a falta de concretude nas consideraçóes, os caminhos apontados mostram-se pouco produtivos no sentido de minimizar o problema em foco ou de superar os obstáculos expostos no estudo. Vejamos dois exemplos: 
(d) T5V2008UFSC - The interdisciplinary nature of this research has attempted to develop an explicit discussion of meaning-making resources. This knowledge can be adapted to the classroom environment as way to discuss the ways language and images are articulated in order to promote apparent natural and acceptable ideologies. Work in the area of multimodality may provide teachers with insightful discussions of teaching/learning process especially within the field of literacy. (Böhlke 2008: 172)

(e) T6VeJeM2012UFSC - there is a clear need for teaching and learning practices that account for the resources of multimodality so that students may become increasingly more apt to function effectively in such global context. With that in mind, the present research will hopefully be welcomed as a further contribution to the understanding of resources other than verbal language, which might allow teachers to work with such new textual configurations in their classes in more theoretically principled ways. (Bezerra 2012: 289)

É preciso pensar em como propiciar ao/à professor/a o acesso a esses trabalhos, a leitura deles e as condiçóes para a abordagem da multimodalidade em sala de aula e para o desenvolvimento de açóes que possam tornar tudo isso efetivo na prática.

Da mesma forma, observamos que em muitas pesquisas falta uma apresentação e discussão de possíveis caminhos para superar ou minimizar os obstáculos e, em alguns casos, são apontados caminhos sem, contudo, se explicitarem os agentes e o detalhamento da ação, o que limita a efetividade das proposiçóes. Em T1MV2015UFPE e em T7MI2011UnB, por exemplo, os/as autores/ as sugerem respectivamente:

(f) T1MV2015UFPE - Como proposta de intervenção política pela ACD, indicamos a contestaçâa dos interesses dos grandes grupos econômicos, dificultando a legitimação de seus interesses. Podemos pensar em um contradiscurso que reflita sobre o problema e possa possibilitar a compreensäo de mensagens subliminares e enganosas que tentam nos impor por meio de estratégias que visam a manipulação e a persuasáo em detrimento do diálogo e da verdade. (Paulino 2015: 277)

(g) T7MI2011UnB - a capacitaçāo dos profissionais e a existência de outras formas de apoio como parcerias com secretarias de desenvolvimento social em todos os estados e municipios seriam muito importantes para a erradicação da violência doméstica e familiar. (Dias 2011: 115)

Considerando essas sugestóes, indagamos: quem articularia e como se daria a contestação proposta? Como o contradiscurso proposto atingiria boa parte da população brasileira? Como as sugestóes de Dias (2011) e seu estudo podem se tornar conhecidos para além das universidades, para que se pense sobre a possibilidade de capacitação de profissionais e de estabelecimento de parcerias? $\mathrm{O}$ que o autor e a autora fizeram para que suas pesquisas fossem conhecidas, para que os problemas em foco fossem debatidos pelo menos por parte da populaçáo mais diretamente envolvida? Nesse sentido, perde-se muito em relação ao potencial de mudança que as pesquisas em ADC podem ter.

A análise revelou ainda que, teoricamente, falamos em mudança social e em crítica, mas pouco fazemos na prática de nossas pesquisas para promover essa mudança e a autocrítica não se faz presente em todos os trabalhos. Conforme Magalhães, Martins e Resende (2017: 163), “A pesquisa 
crítica deve ser, antes de tudo, autocrítica. E isso não pode deixar de incluir profunda reflexão acerca das práticas de pesquisa”.

A autocrítica é apresentada especialmente com referência aos procedimentos metodológicos, como ilustram os excertos a seguir:

(h) T5V2008UFSC - Another limitation of this study involves the fact that the investigation of the images under film format is very recent in the field of multimodal analysis. [...] Given the complexity involving the transcription of moving images, only one television advertisement was selected among the three collected versions. (Böhlke 2008:171)

(i) T5S2014UFMG - Como limitaçóes dessa pesquisa destaca-se inicialmente a minha presença enquanto entrevistadora, pois, o fato de as entrevistadas saberem da minha atuação como consultora de imagem pode as ter levado a uma maior negociação de seus pontos de vista, por meio de modalizaçóes [...] Além disso, o próprio gênero entrevista direcionou as perguntas para o tema desta pesquisa, o que pode ter comprometido a liberdade das participantes na expressäo de suas as ideias. Outra limitação refere-se ao número de participantes; apenas 12. Sugere-se que novas pesquisas sejam feitas com corpus maior e mais variado. (Loiola 2014: 153)

(j) T6VeJeM2012UFSC - One of the greatest challenges in this investigation has been to deal with the analysis of the dynamic image in enough detail and in due time. In order to do, relevant parts of the film have been chosen to make up the data. That choice inevitably invites considerations about whether or not the results found are generalizable across the whole text. Therefore, one limitation of the present research might be the unfeasibility of analyzing more data with as much detail when dealing with the dynamic image. (Bezerra 2012: 288)

Também há autocrítica centrada nas lacunas dos trabalhos e nas dificuldades enfrentadas pelo/a pesquisador/a no tocante ao retorno à comunidade participante, como nestes excertos:

(k) D7A2014UFSC - É preciso afirmar, no entanto, que o trabalho desenvolvido na escola, apesar de midiático, não trouxe para o ambiente escolar uma reflexáo crítica acerca das mídias e seus jogos de poder, deixando de explorar o funcionamento das mídias e náo possibilitando a promoção de uma reflexão sobre como usá-las de forma mais crítica[...] Apesar disso, o trabalho com o gênero textual não foi contemplado da maneira que imaginávamos quando iniciamos a pesquisa naquela escola. Não houve, em nenhum momento, uma discussão acerca da pluralidade dos gêneros e de como o entendimento destes e do trabalho com a linguagem pode favorecer o protagonismo dos sujeitos e a mudança da sociedade, a partir do momento que ideologias sáo interpretadas por meio dos discursos. (Antoniassi 2014: 108)

(l) D10VeF2012UnB - No texto da devolutivalreceptiva, em que procurei ao máximo simplificar a linguagem, ainda assim, não alcancei o que almejava. Hoje, relendo-o com o distanciamento do tempo, vejo que segue hermético, tanto pela seleção lexical quanto pela estrutura que empreguei. A dificuldade quando se trata de equalizar complexidade conceitual e simplicidade comunicativa é enorme, e se delineia como campo a ser explorado em outros trabalhos vindouros. (Acosta 2012: 223) 
Outra lacuna evidenciada em nossa pesquisa diz respeito à dificuldade de se efetivar a inter e a transdisciplinaridade como parte constitutiva da análise e discussão dos dados. Consideramos de suma importância materializar a inter e a transdisciplinaridade em todo o processo de construção da pesquisa e não apenas na fundamentação teórica.

Além disso, há outra lacuna que reside no fato de que a maioria dos/as estudiosos/as contextualiza a teoria, mas não a avalia, e a tomam como dada e incontestável. A preocupação parece ser com a confirmaçáo do potencial da teoria, como ilustra o excerto a seguir:

(m) D3J2012UFPE: O fato de o grupo grevista [...] ter tido mais acesso ao discurso noticioso nos fez ver que a nossa pesquisa se constituía em mais um exemplo de confirmaçāo da teoria abordada por alguns referenciais teóricos (FALCONE, 2005; VAN DIJK, 2008). (Melo 2012: 104)

Isso é decorrência da colonialidade do conhecimento. Limitamo-nos a aprender teorias construídas com base em experiências e em problemas de outra parte do mundo e a aplicá-las em nossos estudos (Grosfoguel: 2016).

Conforme Resende (2010: 193) argumenta:

The colonialism of knowledge in Latin America has led as a consequence to the forming of a body of researchers competent in understanding and applying theories and methods but who are petrified at their own ideas as they Always need to be legitimated by foreign thinkers. [...] The problem is that creativity plays a fundamental role in scientific progress and in creating theory. Our low scientific self-esteem has made us hostage to imported progress given that we do not see ourselves in many instances as being able to contribute effectively in developing the theories we use - although we are always ready to apply the most recent literature published, without reflecting at times with due parsimony on the applicability of imported categories and concepts to our local research contexts.

Nós concordamos com a autora e acreditamos que ainda é um desafio para a maioria dos/as pesquisadores/as em ADC contribuir para os avanços da teoria, por meio da problematização de sua coerência, de seus pressupostos e da apresentação de novas proposições teórico-metodológicas mais voltadas para a "nossa própria identidade latino-americana" (Pardo 2019: 48). Entendemos que é necessário que se faça uma reflexão sobre a teoria, que se leve em conta o fato de que a ADC foi desenvolvida em um contexto totalmente diferente do brasileiro e que se considere a perspectiva decolonialista como necessária nos estudos em ADC.

Há vários anos a temática da colonização e da decolonização do conhecimento tem sido estudada, como representado na obra organizada por Lander (2000), que reúne textos de Enrique Dussel, Walter D. Mignolo, Santiago Castro-Gómez, Aníbal Quijano, dentre outros. Entretanto, como destaca Pardo (2010; 2019), as reflexóes sobre a temática, especialmente em se tratando da produção na área do discurso, situada na América Latina, são mais recentes, mas estáo sendo cada vez mais ampliadas. Elas têm apontado, por exemplo, para a necessidade de contemplarmos temáticas que representem a nossa realidade, de criarmos teorias e métodos voltadas para essa realidade, de tomarmos produçôes latinas como fontes teóricas e metodológicas, o que não significa desconsiderar o conhecimento já construído, mas, sim, "despertar um pensamento crítico e uma açáo que nos levem a gerar teorias e métodos próprios, assim como uma revalorização de nosso próprio fazer" (Pardo 2019: 52). 


\section{Consideraçóes finais}

O estudo, cujos resultados parciais apresentamos neste artigo, distingue-se dos já realizados no Brasil por diferentes características. A primeira delas diz respeito a sua novidade, uma vez que constitui uma representação da pesquisa brasileira em ADC no período de 2008 a 2017. A segunda delas é relativa à abrangência do trabalho, tanto temporal quanto geográfica, pois além de contemplar a produção de uma década, diferentemente de outras pesquisas já desenvolvidas, inclui produçáo oriunda de seis programas de pós-graduação acadêmicos de quatro instituiçóes de ensino superior, de quatro regiōes brasileiras. A terceira delas corresponde ao escopo da análise, a qual engloba diferentes aspectos teóricos e metodológicos. A quarta refere-se à avaliaçáo desses trabalhos em termos de possíveis lacunas e contribuiçóes teóricas e metodológicas.

Tudo isso possibilitou o delineamento do estado da arte nesse campo e pode jogar luz ao desenho de novas propostas de estudo em ADC. No que concerne a essas novas propostas, gostaríamos de finalizar este artigo apresentando alguns pontos a serem incluídos em uma agenda de pesquisa em ADC, em consonância com o que defendem Chilton e Wodak (2005: XIII): "Scholars in different cultures will themselves establish their own agenda, one in which the nature, objectives and targets of CDA itself will in all likelihood be creatively transformed".

Sabemos que há anos várias questôes têm sido apontadas como importantes para uma agenda de pesquisa em ADC e nosso propósito aqui não é repeti-las, mas, sim, à luz das lacunas que identificamos, elencar alguns aspectos a serem levados em conta e discutidos nos estudos com base em ADC a serem produzidos no Brasil:

1. materialização da transdisciplinaridade na análise dos dados;

2. exercício da autocrítica e não só da crítica;

3. propostas concretas para minimizar os problemas sociais em evidência nos estudos, com explicitação de agentes e com o detalhamento para sua efetivação;

4. inclusão necessária do retorno à comunidade participante dos resultados das investigações, da discussão com ela desses resultados e de possibilidades para minimizar o problema social enfocado;

5. formação e qualificação de professores;

6. investimento maior na decolonização da $\mathrm{ADC}$ e na ousadia de se propor uma ADC voltada para questóes latino-americanas;

7. contribuiçóes que o Brasil pode dar ao desenvolvimento da ADC;

8. retroalimentaçáo da teoria à luz dos resultados dos estudos produzidos no Brasil;

9. utilização de softwares voltados para a pesquisa qualitativa, para potencializar a análise de amostras maiores de dados;

10. problematizaçáo da coerência e dos pressupostos da $\mathrm{ADC}$, com vistas à contribuição para seu avanço.

Esperamos que a representação da pesquisa brasileira em ADC nos 10 anos em foco, construída neste artigo, contribua para o delineamento do estado da arte nesse campo, para uma reflexão sobre nossas próprias pesquisas em $\mathrm{ADC}$ e para o desenho de novas propostas de estudo que superem os limites da herança colonial e da academia eurocentrada, que se voltem para modos decoloniais de pesquisar, de conhecer, de ser e de estar no mundo. 
Certamente, essa representação pode ser complementada por meio da inclusão de estudos produzidos em outras universidades do Brasil, em pesquisas futuras.

\section{Referências bibliográficas}

Acosta, M. P. T. 2012. Protagonismo face à inevitabilidade da violência: vozes da rua em Ocas" e em O trecheiro. 232 f. Dissertação (Mestrado em Linguística), Universidade de Brasília, Brasília.

Antoniassi, P. I. C. 2014. O jornal escolar e a formação de alunos produtores de textos: análise de uma prática de letramento midiático em uma escola municipal de Florianópolis - SC. $141 \mathrm{f}$. Dissertação (Mestrado em Linguística), Universidade Federal de Santa Catarina, Florianópolis.

Baldry, A. e Thibault, P. J. 2006. Multimodal transcription and text analysis: a multimedia toolkit and coursebook with associated on-line course. London: Equinox.

Bezerra, F. A. S. 2012. Language and image in the film sex and the city: a multimodal investigation of the representation of women. 307 p. Tese (Doutorado em Letras), Universidade Federal de Santa Catarina, Florianópolis.

BöHLKe, R. F. 2008. Constructing ideal body appearance for women: a multimodal analysis of a TV advertisement. Tese (Doutorado em Letras), Universidade Federal de Santa Catarina, Florianópolis.

Caldas-Coulthard, C. R. 1997. News as social practice: a study in critical discourse analysis. Florianópolis: Editora da UFSC.

Camargo, M. E. S. 2014. Teses e dissertaçôes em análise do discurso na região centro-oeste: aspectos históricos e discursivos. $161 \mathrm{f}$. Dissertação (Mestrado em Letras) Universidade Federal da Grande Dourados, Dourados.

Cavalcanti, M. C. C. 2013. Campanha de conscientização ambiental: prática social e discursiva na modernidade tardia. Tese (Doutorado em Letras), Universidade Federal de Pernambuco, Recife.

Chilton, P. e Wodak, R. 2005. Preface. Em R. Wodak, R . e P. Chilton (eds.). A New Agenda in (Critical) Discourse Analysis: Theory, methodology and interdisciplinarity, pp. XI-XVIII. Amsterdam/ Philadelphia: John Benjamins.

Chouliaraki, L. e Fairclough, N. 1999.Discourse in late modernity: rethinking critical discourse analysis. Edinburgo: Edinburgh University Press.

Dias, T. R. N. 2011. Prática Jurídica e Violência contra Mulheres: Um Estudo Etnográfico-Discursivo. 208 f. Tese (Doutorado em Linguística, Universidade de Brasília, Brasília.

Fairclough, N. 1985. Critical and descriptive goals in discourse analysis. Journal of Pragmatics, 9: 739-763.

FAirclough, N. 2009. A dialectical-relational approach to critical discourse analysis in social research. Em R. Wodak e M. Meyer (eds.). Methods of critical discourse analysis. 2. ed., pp. 162-186. Londres: Sage. 
FalCone, K. 2003. O acesso dos excluídos ao espaço discursivo do jornal. 159 f. Dissertação (Mestrado em Letras/Linguística). Universidade Federal de Pernambuco, Recife.

Ferreira, N. S. A. 2002. As pesquisas denominadas "estado da arte". Educaçâo \& Sociedade, XXIII (79): 257-272.

Grosfoguel, R. 2016. A estrutura do conhecimento nas universidades ocidentalizadas: racismo/ sexismo epistêmico e os quatro genocídios/epistemicídios do longo século XVI. Sociedade e estado, 31 (1): $25-49$.

Jones, R. H. e Norris, S. 2005. Discourse in action: introducing mediated discourse analysis. New York: Routledge.

Kress, G. e van Leeuwen, T. 1996. Reading images: the grammar of visual design. Londres; Nova York: Routledge.

LANDER, E. (ed.). 2000. La colonialidad del saber:eurocentrismo y ciencias sociales. Perspectivas latinoamericanas. Buenos Aires: CLACSO.

Loiola, R. F. 2014. Análise discursiva da autoimagem corporal de mulheres em diferentes idades: espelho, espelho meu! 242 f. Tese (Doutorado em Estudos Linguísticos), Universidade Federal de Minas Gerais, Belo Horizonte.

Magalhấes, I. 1986. Por uma abordagem crítica e explanatória do discurso. D.E.L.T.A., 2 (2): 181-205.

Magalhães, I. 2000. Eu e Tu: a constituição do sujeito no discurso médico. Brasília: Thesaurus.

Magalhâes, I. 2006. Discurso, ética e identidades de gênero. Em I. Magalhães, M. Grigoletto, M. J. Coracini (orgs.). Práticas identitárias. Lingua e discurso, pp. 71-96. São Carlos: Claraluz.

Magalhâes, I., Martins, A. R. e Resende, V. M. 2017. Análise de Discurso Crítica: um método de pesquisa qualitativa. Brasília: Editora Universidade de Brasília.

McCracken, G. D. 1988. The long interview. Qualitative Research Methods-volume 13. Newbury Park, Londres, Nova Delhi: Sage.

Melo, L. N. T. 2012. Construção de identidade de grevistas pela imprensa. 138 f. Dissertação (Mestrado em Letras), Universidade Federal de Pernambuco, Recife.

Nicoloso, S. 2010. Uma investigação sobre marcas de gênero na interpretaçâo de língua de sinais brasileira. 200 f. Dissertação (Mestrado em Estudos da Tradução), Universidade Federal de Santa Catarina, Florianópolis.

Norris, S. 2004. Analyzing Multmodal Interaction: a methodological framework. New York: Routledge.

NorRIs, S. 2011. Identity in (Inter)action: Introducing Multimodal (Inter)action Analysis. Berlin, Boston: deGruyter Mouton. 
Painter, C. e Martin, J. R. 2011. Intermodal complementarity: modelling affordances across image and verbiage in children's picture books. Em F. Yan (ed.). Studies in functional linguistics and discourse analysis 3, pp. 132-158. Beijing: Higher Education Press.

PARdo, M. L. 2010. Latin-American discourse studies: state of the art and new perspectives. Journal of Multicultural Discourses, 5(3): 183-192.

PARdo, M. L. 2011. Teoria y metodologia de la investigación lingüistica: método sincrónico-diacrónico de análisis linguistico de textos. Buenos Aires: Tersites.

Pardo, M. L. 2019. Decolonização do conhecimento nos estudos do discurso. Em V. de M. Resende (org.). Decolonizar os Estudos Críticos do Discurso, pp. 47-62. Campinas, SP: Pontes Editores.

Paulino, S. F. 2015. Análise crítica do discurso econômico-moral de publicidades bancárias. $296 \mathrm{f}$. Tese (Doutorado em Letras/Linguística), Universidade Federal de Pernambuco.

Pedrosa, C. E. F. e Cruz, R. 2012. Análise Crítica do Discurso: mapeando pesquisas de aplicaçóes pedagógicas em sala de aula. Em Congresso Brasileiro de Linguística Aplicada, 9, 2012, Rio de Janeiro. Anais eletrônicos. Rio de Janeiro, 1 (1): p. 1-17.

Ramalho, V. e Resende, V. M. 2011. Análise de discurso (para a) crítica: o texto como material de pesquisa. Campinas: Pontes Editores.

Resende, V. M. 2010. Between the European legacy and critical daring: epistemological reflections for critical discourse analysis. Journal of Multicultural Discourses, 5(3): 193- 212.

Resende, V. M. (org.). 2019. Decolonizar os Estudos Críticos do Discurso. Campinas, SP: Pontes Editores.

Resende, V. M. e Ramalho, V. C. V. S. 2004. Análise de discurso crítica, do modelo tridimensional à articulação entre práticas: implicaçóes teórico-metodológicas. Linguagem em (Dis)curso - LemD, 5(1): 185-207.

Rodrigues, M. F. G. 2010. Análise constitutiva do discurso das mães de crianças em tratamento fonoaudiológico sobre a interação com o profissional. 158 f. Dissertação (Mestrado em Linguística), Universidade Federal de Minas Gerais, Belo Horizonte.

Rose, G. 2007. Visual methodologies: an introduction to the interpretation of visual methods. UK: Sage Publications.

Rossetto, G. A. R. S. et al. 2013. Desafios dos estudos “Estados da arte”: estratégias de pesquisa na pós-graduação. Educação: Saberes e Práticas, 1: 1-15.

SAntos, G. P. 2017. A voz da situação de rua na agenda de mudança social no Brasil: um estudo discursivo-crítico sobre o Movimento Nacional da População em Situação de Rua (MNPR). 264 p. Tese (Doutorado em Linguística), Universidade de Brasília, Brasília.

Santos, M. L. D. M. 2009. Vozes na rua: práticas de leitura e escrita e construção de uma nova imagem do morador em situação de rua. 317 f. Dissertação (Mestrado em Estudos Linguísticos), Universidade Federal de Minas Gerais, Belo Horizonte. 
TAtagiba, A. B. 2014. Dos letramentos às mudanças discursivas e sociais na educação escolar de pessoas jovens, adultas e idosas. $186 \mathrm{f}$. Dissertação (Mestrado em Linguística), Universidade de Brasília, Brasília.

Van Dijk, T. A. 2008. Discurso e poder. Org. por Judith Hoffnagel e Karina Falcone. São Paulo: Contexto.

WoDAK, R. 2001. What CDA is about: a summary of its history, important concepts and its development. Em R.Wodak e M. Meyer (orgs.). Methods of critical discourse analysis, p. 1-13. Londres; Thousand Oaks; Nova Delhi: Sage.

Wodak, R. e Meyer, M. 2009. Critical Discourse Analysis: history, agenda, theory and methodology. Em R. Wodak e M. Meyer (eds.). Methods of critical discourse analysis. 2. ed., pp. 1-33. Londres: Sage.

Wodak, R. e Meyer, M. (eds.). 2009. Methods of critical discourse analysis. 2. ed. Londres: Sage.

MARIA APARECIDA RESENDE OTTONI é doutora em Linguística pela Universidade de Brasília (UnB). É professora associada do Instituto de Letras e Linguística da Universidade Federal de Uberlândia (UFU). É pesquisadora do Programa de Pós-Graduação em Estudos Linguísticos (PPGEL/UFU), orientando na linha de pesquisa Linguagem, sujeito e discurso, e do Programa de Pós-Graduação Mestrado Profissional em Letras (PROFLETRAS/UFU), orientando na linha de pesquisa Estudos da Linguagem e Práticas sociais. É líder do Grupo de Pesquisas e Estudos em Análise de Discurso Crítica e Linguística Sistêmico-Funcional e membro do Núcleo de Estudos de Linguagem e Sociedade (NELiS/Ceam/UnB).

E-mail: cidottoni@gmail.com

IZABEL MAGALHÁES possui doutorado em Linguística e pós-doutorado pela Universidade de Lancaster, Reino Unido. Foi fundadora do Doutorado em Linguística e do periódico Cadernos de Linguagem e Sociedade, da Universidade de Brasília (UnB). Foi Professora Visitante na Universidade Federal do Ceará, e atualmente é Pesquisadora Colaboradora da UnB e Professora Visitante na Universidade Federal de Goiás. Membro efetivo da Associação Latino-Americana de Analistas do Discurso, da Associação Brasileira de Linguística e da Associação de Linguística Aplicada do Brasil, e pesquisadora/consultora do Conselho Nacional de Desenvolvimento Científico e Tecnológico, nível 1D. Publicou várias obras e tem experiência na área de Linguística e Linguística Aplicada, atuando principalmente nos seguintes temas: análise de discurso, letramento, gênero e linguagem, linguagem e saúde, identidades, e metodologia etnográfica.

E-mail: izabelunb@gmail.com 